\title{
Characterization of $\mathrm{P}_{1}$-purinoceptors on rat duodenum and urinary bladder
}

\author{
J. Nicholls, ${ }^{1}$ S.M.O. Hourani \& I. Kitchen \\ Receptors \& Cellular Regulation Research Group, School of Biological Sciences, University of Surrey, Guildford, Surrey \\ GU2 5XH
}

1 The $\mathrm{P}_{1}$-purinoceptors mediating relaxation of the rat duodenum and inhibition of contraction of the rat urinary bladder were characterized by use of adenosine and its analogues $5^{\prime}$ - $\mathrm{N}$-ethylcarboxamidoadenosine (NECA), $\mathbf{N}^{6}$-cyclopentyladenosine (CPA) and 2-p-((carboxyethyl)phenethylamino) -5'-carboxamidoadenosine (CGS 21680), as well as the $A_{1}$-selective antagonist 1,3-dipropyl-8-cyclopentylxanthine (DPCPX). The stable analogue of adenosine $5^{\prime}$-triphosphate (ATP), adenylyl $5^{\prime}-(\beta, \gamma$-methylene)diphosphonate (AMPPCP), was also used as previous work had indicated that it has a direct action on some $P_{1}$ receptors in addition to its $P_{2}$-purinoceptor activity.

2 In the rat duodenum, the order of potency of the adenosine agonists was NECA $\geqslant$ CPA > AMPPCP = adenosine > CGS 21680, and DPCPX antagonized CPA and AMPPCP at a concentration of $1 \mathrm{nM}$ whereas equivalent antagonism of NECA and adenosine required a concentration of $1 \mu \mathrm{M}$. This suggests the presence of a mixture of $A_{1}$ and $A_{2}$ receptors in this tissue, with CPA and AMPPCP acting on the $A_{1}$ and NECA and adenosine acting on the $A_{2}$ receptors.

3 In the rat bladder, the order of potency of the adenosine agonists for inhibition of carbachol-induced contractions was NECA $\gg$ adenosine $>$ CPA $=$ CGS 21680 , and a concentration of DPCPX of $1 \mu \mathrm{M}$ was required to antagonize responses to NECA and adenosine. This suggests the presence of $A_{2}$ receptors in this tissue. ATP and AMPPCP each caused contractions which were not enhanced by DPCPX $(1 \mu \mathrm{M})$ which suggests that in this tissue AMPPCP was acting only via $P_{2}$ receptors and had no $P_{1}$ agonist activity. That AMPPCP was active on the $A_{1}$ receptors in the duodenum but inactive on the $A_{2}$ receptors in the bladder implies that it has selectivity for the $A_{1}$ subtype.

4 That CGS 21680, which has been reported to bind selectively to the high affinity $A_{2 a}$ subclass of $A_{2}$ receptors, had a very low potency on the $A_{2}$ receptors in the duodenum and in the bladder suggests that these receptors are of the low affinity $A_{2 b}$ subclass.

Keywords: Adenosine; ATP; purinoceptors; duodenum; bladder

\section{Introduction}

Adenosine and adenine nucleotides have pharmacological actions on a variety of smooth muscle preparations, and these effects are mediated via receptors which have been classified as $P_{1}$ - and $P_{2}$-purinoceptors, recognising adenosine and adenosine 5'-triphosphate (ATP) respectively (Burnstock, 1990; Kennedy, 1990). Studies with ATP are complicated by its rapid dephosphorylation by ectonucleotidases present on smooth muscle preparations, to give adenosine which has its own effects (Slakey et al., 1990).

$\mathbf{P}_{\mathbf{2}}$-purinoceptors on smooth muscle have been subdivided into $P_{2 X}$, usually mediating contraction, and $P_{2 Y}$, usually mediating relaxation, and this classification is largely based on the different structure-activity relationships of ATP analogues in causing these two effects (Burnstock \& Kennedy, 1985; Gordon, 1986; Kennedy, 1990; Cusack \& Hourani, 1990). For $\mathbf{P}_{2 \mathrm{x}}$-purinoceptors, methylene phosphonate analogues of ATP such as adenylyl $5^{\prime}$-( $\beta, \gamma$-methylene)diphosphonate (AMPPCP) and adenosine $5^{\prime}$ - $(\alpha, \beta$-methylene)triphosphonate (AMPCPP), which are resistant to dephosphorylation, are more potent than ATP which is equipotent with 2-substituted analogues such as 2-methylthioadenosine 5'-triphosphate (MeSATP), whereas on $P_{2 y}$-purinoceptors MeSATP is more potent than ATP which is more potent than AMPPCP or AMPCPP. However, these structure-activity relationships may be partly dependent on the different sensitivities to degradation of the analogues by ectonucleotidases, which appears to enhance their potency on some tissues but not on others (Welford et al., 1986; 1987).

$P_{1}$-purinoceptors have been subdivided into $A_{1}$ and $A_{2}$ according to the potency of adenosine analogues and their sensitivity to $A_{1}$-selective antagonists such as 1,3-dipropyl-8-

\footnotetext{
${ }^{1}$ Author for correspondence.
}

cyclopentylxanthine (DPCPX). On $A_{1}$ receptors, $N^{6}$ substituted analogues such as $\mathrm{N}^{6}$-cyclopentyladenosine (CPA) are more potent than $5^{\prime}$-substituted analogues such as $5^{\prime}-\mathrm{N}$ ethylcarboxamidoadenosine (NECA), and DPCPX has a dissociation constant in the nanomolar range, whereas on $A_{2}$ receptors NECA is more potent than CPA and DPCPX has a dissociation constant in the micromolar range (Bruns, 1990; Kennedy, 1990). Because the affinities of adenosine agonists are generally less for $A_{2}$ than for $A_{1}$ receptors, NECA is not selective for $A_{2}$ receptors but has roughly equal potency on each subtype, but a new analogue, 2-p-((carboxyethyl)phenethylamino)-5'-carboxamidoadenosine (CGS 21680) has recently been developed and reported to be highly $A_{2}$-selective (Hutchison et al., 1989; Jacobson, 1990). Although some problems have been encountered in the classification of $\mathbf{P}_{1}$-purinoceptors in smooth muscle, as compounds which have been reported to be selective in the central nervous system do not always display selectivity in the periphery, DPCPX has been shown to discriminate clearly between the $\mathrm{A}_{1}$ and $\mathrm{A}_{2}$ subtypes in pharmacological studies (Collis et al., 1989; Collis, 1990).

Little is known about the ontogeny of purinergic systems in smooth muscle, but we have studied the development of responses to adenosine and ATP in two tissues, the rat duodenum and urinary bladder. In each tissue responses to purines are present from birth, and in some cases the potency of the purines is considerably higher in the neonate than in the adult, indicating that purines may play an important role in neonatal tissues. The rat duodenum relaxes to ATP and the rat bladder contracts, and these responses, as expected, are mediated by $P_{2 Y^{-}}$and $P_{2 X}$-purinoceptors respectively. In the neonatal rat duodenum however, ATP causes contraction rather than relaxation, and this contraction is also mediated by $\mathbf{P}_{2 \mathrm{Y}}$-purinoceptors and is not due to secondary release of prostaglandins (Nicholls et al., 1990). Adenosine is inhibitory 
in both these tissues, but the subtype of $P_{1}$-purinoceptor which mediates its responses has not been defined so far. In the duodenum we have shown that AMPPCP acts unexpectedly via $P_{1}$ and not $P_{2}$-purinoceptors to cause relaxation, as its effects are inhibited by the $P_{1}$ antagonist 8-p-sulphophenyltheophylline (8-SPT), whereas the effects of ATP MeSATP and AMPCPP are not inhibited (Hourani et al., 1991). The ontogeny of responses of the duodenum to AMPPCP also mirrors that of adenosine rather than of ATP and indeed AMPPCP is never observed to induce contraction (Nicholls et al., 1990). We have also shown an anomolous $P_{1}$ effect of AMPPCP in another smooth muscle preparation, the rat colon muscularis mucosae (Bailey \& Hourani, 1990), and to a lesser extent in the guinea-pig taenia caeci (Hourani et al. 1991). The $P_{1}$ effect of AMPPCP in these tissues is direct and not a consequence of its breakdown to adenosine, as it is much more resistant to degradation than is ATP or MeSATP which are not inhibited by 8-SPT (Bailey \& Hourani, 1990; Hourani et al., 1991). In the rat duodenum, a ten fold lower concentration of 8-SPT was required to inhibit the effects of AMPPCP than to inhibit the effects of adenosine, which could indicate that their effects were mediated by different $\mathrm{P}_{1}$-purinoceptors as 8-SPT has been reported to be selective for $A_{1}$ receptors in the central nervous system (Bruns et al., 1986), although it may not discriminate between the subtypes in smooth muscle (Collis et al., 1987). We therefore decided to use the more selective antagonist DPCPX, together with the agonists NECA, CPA and CGS 21680, to characterize the $P_{1}$-purinoceptor subtypes in the rat duodenum and urinary bladder.

\section{Methods}

Adult male Wistar rats (200-250 g) were killed by cervical dislocation, and the duodenum and urinary bladder dissected out and responses quantified as described in Nicholls et al. (1990). Briefly, the tissues were mounted in $10 \mathrm{ml}$ organ baths containing Krebs buffer of the following composition (mM): $\mathrm{NaCl}$ $118, \mathrm{KCl} 4.8, \mathrm{MgSO}_{4} 1.2, \mathrm{CaCl}_{2} 2.5, \mathrm{KH}_{2} \mathrm{PO}_{4} 1.2, \mathrm{NaHCO}_{3}$ 25 and glucose 11 , aerated with $95 \% \mathrm{O}_{2} / 5 \% \mathrm{CO}_{2}$ and maintained at $35^{\circ} \mathrm{C}$. A resting tension of $1 \mathrm{~g}$ was applied to the tissues, and isometric responses were recorded with a Grass FT03 transducer and displayed on a Grass 79D polygraph. Tissues were equilibrated for $45 \mathrm{~min}$ before addition of drugs, concentration-response curves were obtained noncumulatively and potency estimates $\left(\mathrm{EC}_{50}\right.$ values) were obtained from linear regression analysis of the ascending linear portion of the individual concentration-response curves. For the duodenum, inhibitory responses were quantified by pre-contracting the tissue with $0.1 \mu \mathrm{M}$ carbachol before challenging with agonist, and the relaxation expressed as \% inhibition of this carbachol-induced contraction. For the bladder, excitatory responses to ATP and to AMPPCP were expressed as $\%$ of the maximal contraction induced by $\mathrm{KCl}(120$ $180 \mathrm{~mm})$. The inhibitory effects of adenosine and its analogues were expressed as \% inhibition of carbachol contraction, where the purines were added $30 \mathrm{~s}$ before challenge with carbachol $(3 \mu \mathrm{M})$. In each tissue, after control concentrationresponse curves had been obtained, the tissues were incubated for $30 \mathrm{~min}$ with DPCPX, and the concentration-response curves repeated in the presence of the antagonist. Dose-ratios were calculated from the ratio of the $\mathrm{EC}_{50}$ values in the absence and presence of antagonist, and dissociation constants ( $K_{\mathrm{D}}$ values) were calculated as the molar concentration of the antagonist divided by the dose-ratio - 1 . In some experiments with the duodenum, hexamethonium $(10 \mu \mathrm{M})$ was used as a nicotinic antagonist with the same protocol as DPCPX, and dimethylphenylpiperazinium (DMPP) was used as a nicotinic agonist.

\section{Materials}

Adenosine, ATP, AMPPCP, NECA, DMPP, carbachol and hexamethonium were obtained from Sigma UK, Ltd, and
DPCPX, CPA and CGS 21680 from Research Biochemicals Inc. CPA (1 mM) was dissolved in $2 \%$ ethanol and DPCPX (1 mM) in $2 \%$ aqueous dimethylsulphoxide (DMSO) containing $6 \mathrm{mM} \mathrm{NaOH}$. After dilution corresponding to the final bath concentration of the substances used, these solvents had no effect on the responses of the tissues.

\section{Results}

\section{Rat duodenum}

Adenosine, AMPPCP, CPA, NECA and CGS 21680 all relaxed the carbachol-contracted rat duodenum, the order of potency being NECA $\geqslant$ CPA $>$ AMPPCP $=$ adenosine $>$ CGS 21680, and the $\mathrm{EC}_{50}$ values of these compounds were $0.4 \mu \mathrm{M}, 0.7 \mu \mathrm{M}, 18 \mu \mathrm{M}, 28.5 \mu \mathrm{M}$ and $98 \mu \mathrm{M}$ respectively (Figure 1). DPCPX (1 nM) caused a parallel shift to the right of the concentration-response curves to AMPPCP and CPA, giving dose-ratios of 6.7 and 5.7, corresponding to $K_{\mathrm{D}}$ values of $0.18 \mathrm{~nm}$ and $0.21 \mathrm{nM}$, respectively (Figures $2 \mathrm{a}, \mathrm{b}$ ), but had no effect on the concentration-response curves to adenosine or NECA (Figures $2 \mathrm{c}, \mathrm{d}$ ). At $1 \mu \mathrm{M}$, DPCPX did cause shifts in the concentration-response curves to adenosine and NECA, giving dose-ratios of 6.3 and 6.7, corresponding to $K_{\mathrm{D}}$ values of $0.19 \mu \mathrm{M}$ and $0.18 \mu \mathrm{M}$, respectively (Figures $2 \mathrm{e}, \mathrm{f})$. DMPP $(0.1-$ $100 \mu \mathrm{M})$ caused relaxation of the rat duodenum, followed at high concentrations by contraction, and these effects were inhibited by hexamethonium $(10 \mu \mathrm{M})$, which had no effect on the contractions induced by carbachol, or on the concentration-response curves to AMPPCP or to CPA (results not shown).

\section{Rat urinary bladder}

Adenosine and NECA each inhibited contractions of the rat bladder induced by carbachol $(3 \mu \mathrm{M})$, and the order of potency was NECA $\gg$ adenosine, the $\mathrm{EC}_{50}$ values being $1.6 \mu \mathrm{M}$ and $92 \mu \mathrm{M}$ respectively (Figure 3a). CPA and CGS $21680(10 \mu \mathrm{M})$ also weakly inhibited carbachol-induced contractions, but $\mathrm{EC}_{50}$ values could not be obtained due to their low potency (results not shown). DPCPX $(1 \mu \mathrm{M})$ caused parallel shifts to the right of the concentration-response curves for NECA and adenosine, giving dose-ratios of 5.7 and 6.3, corresponding to $K_{\mathrm{D}}$ values of $0.21 \mu \mathrm{M}$ and $0.19 \mu \mathrm{M}$, respectively (Figure 3a). ATP and AMPPCP each contracted the rat urinary bladder, and these contractions were not enhanced by DPCPX $(1 \mu \mathrm{M})$ (Figure 3b).

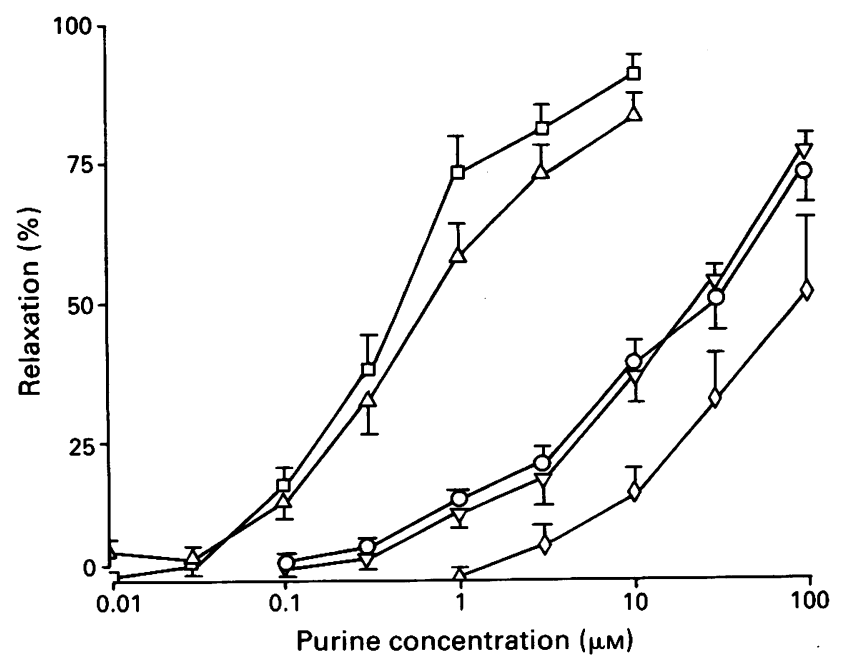

Figure 1 Relaxation of the rat duodenum induced by NECA ( $\square$ ), CPA $(\triangle)$, AMPPCP $(\nabla)$, adenosine $(O)$ and CGS $21680(\diamond)$. Each point is the mean of at least nine determinations, and the vertical bars show s.e.mean. For abbreviations, see text. 

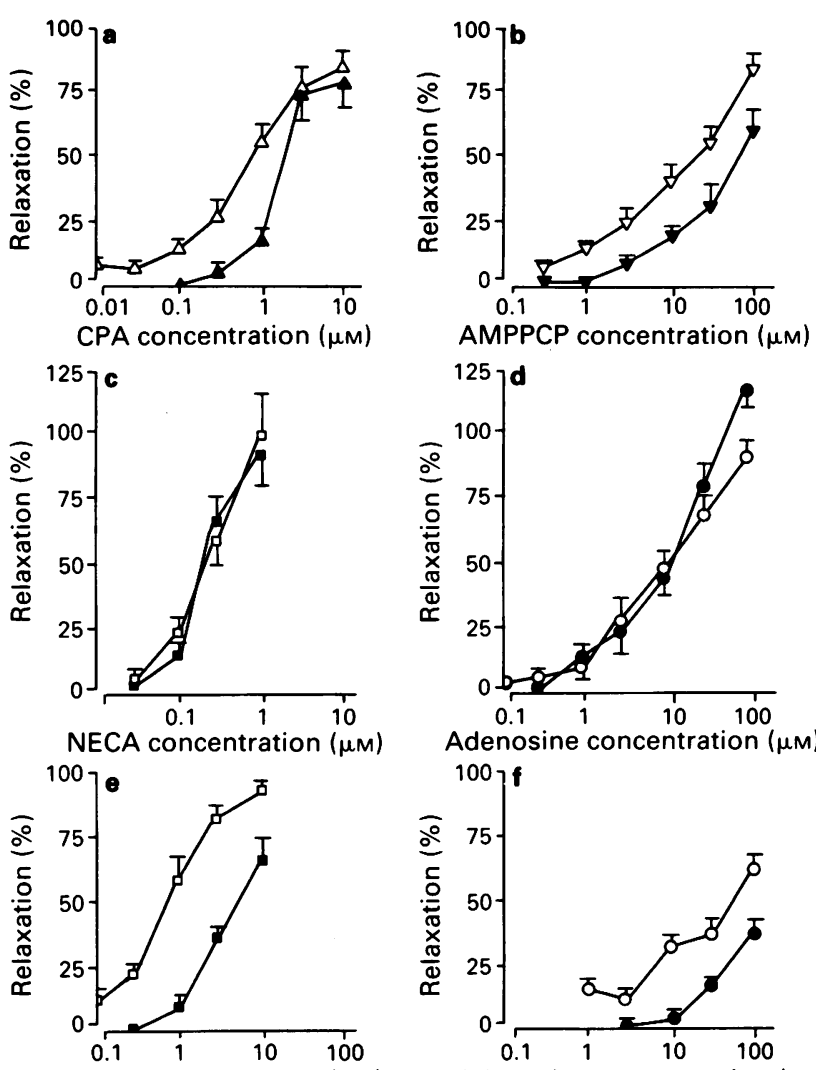

NECA concentration ( $\mu \mathrm{M})$
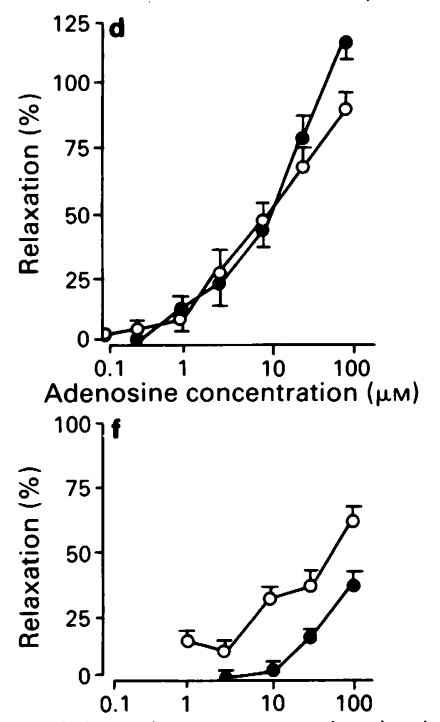

Adenosine concentration ( $\mu \mathrm{M})$

Figure 2 Relaxation of the rat duodenum induced by purines in the absence (open symbols) or presence (closed symbols) of DPCPX. (a) $\mathrm{CPA} \pm \mathrm{DPCPX} \quad(1 \mathrm{nM}), \quad$ (b) AMPPCP \pm DPCPX (1 nM), (c) NECA \pm DPCPX (1 nM), (d) adenosine \pm DPCPX (1 nM), (e) NECA \pm DPCPX $(1 \mu \mathrm{M})$, (f) adenosine \pm DPCPX $(1 \mu \mathrm{M})$. Each point is the mean of at least seven determinations, and the vertical bars show s.e.mean. For abbreviations, see text.

\section{Discussion}

These results show that in the duodenum all the adenosine receptor agonists used caused relaxation, but that the order of potency did not fall clearly into one of the two expected patterns for $A_{1}$ or $A_{2}$ receptors, as NECA and CPA were almost equipotent. Similar results have been interpreted to imply the existence of a third class of adenosine receptor, which has been called $\mathrm{A}_{3}$ (Ribeiro \& Sebastiao, 1986), but this suggestion has not gained wide acceptance. Our results with DPCPX show that whereas CPA and AMPPCP were inhibited by an $A_{1}$-selective concentration of DPCPX $(1 \mathrm{nM})$, much higher concentrations $(1 \mu \mathrm{M})$ were required to inhibit adenosine or NECA. This suggests that the duodenum contains a mixture of $A_{1}$ and $A_{2}$ receptors, with NECA and adenosine acting on the $A_{2}$ population and being inhibited by DPCPX with a dissociation constant in the micromolar range, whereas CPA and AMPPCP act on the $A_{1}$ receptors and are inhibited by DPCPX with a dissociation constant in the nanomolar range. The log concentration-response curve to CPA was somewhat steeper in the presence of $1 \mathrm{nM}$ DPCPX, suggesting that at high concentrations CPA may be acting on the $A_{2}$ receptors as well. It is possible that in other tissues where NECA and CPA are equipotent, the same explanation may apply, and that a mixture of $A_{1}$ and $A_{2}$ receptors may account for the proposed $A_{3}$ subclass.

The significance of the presence of two $P_{1}$-purinoceptor subclasses both mediating an inhibitory response is unclear, as in general in smooth muscle $A_{2}$ receptors mediate relaxation whereas $A_{1}$ receptors mediate presynaptic inhibition of transmitter release or postsynaptic contractile responses (White, 1988; Kennedy, 1990). Although in several tissues, such as the
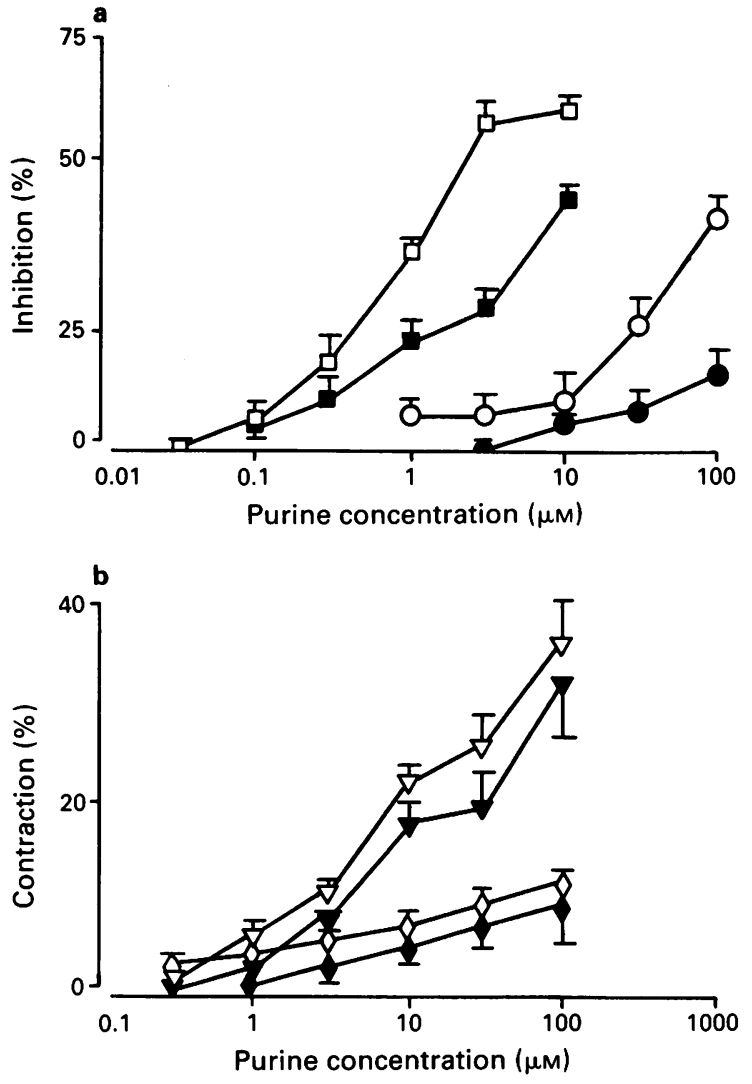

Figure 3 Effects of purines on rat urinary bladder in the absence (open symbols) or presence (closed symbols) of DPCPX $(1 \mu \mathrm{M})$. (a) Inhibitory actions of NECA $(\square, \square)$ and adenosine $(O, O)$ on carbachol-induced contractions. (b) Contractile effects of AMPPCP $(\nabla, \nabla)$ and ATP $(\diamond, \diamond)$. Each point is the mean of at least five determinations, and the vertical bars show s.e.mean. For abbreviations, see text.

guinea-pig trachea and aorta, the presence of both subclasses of $P_{1}$-purinoceptor has been reported, in each case the $A_{1}$ receptor mediates contraction while only the $A_{2}$ mediates relaxation (Farmer et al., 1988; Stoggall \& Shaw, 1990). For two receptor subtypes to mediate the same response in one tissue preparation is unusual, and it is not at all clear why such an apparently redundant system should have evolved. One possible explanation for the relaxant $A_{1}$ effect we have observed is that the carbachol used to precontract the tissues could have been stimulating ganglionic nicotinic receptors to cause release of acetylcholine or some other excitatory transmitter, with the $A_{1}$ receptors being situated presynaptically to oppose this release. However, the initial response to the nicotinic agonist DMPP was relaxation rather than contraction, as found by Manzini et al. (1985) who suggested that this is due to ganglionic stimulation of purinergic nerves. Hexamethonium at a concentration sufficient to block nicotinic receptors $(10 \mu \mathrm{M})$ inhibited these responses to DMPP but did not inhibit the carbachol-induced contractions, suggesting that carbachol was acting directly on the muscle. In addition, hexamethonium did not affect the responses to the $A_{1}$ agonists, which again suggests that they were not acting on presynaptic receptors.

The results with the rat bladder show that the $P_{1}$-purinoceptor mediating inhibition of contraction in this tissue is of the $A_{2}$ class, as NECA was much more potent than CPA and a high concentration $(1 \mu \mathrm{M})$ of DPCPX was required to antagonize adenosine or NECA, an $A_{1}$-selective concentration (1 nM) having no effect. The log concentration-response curve to NECA was somewhat flattened by DPCPX $(1 \mu \mathrm{M})$, suggesting that it may not be having a solely competitive effect here. ATP and AMPPCP, which act at 
$P_{2 x}$-purinoceptors in this tissue to cause contraction, do not appear to have any action on the $A_{2}$ receptors in this tissue, as their contractions were not enhanced by blockade of $P_{1}$-purinoceptors by DPCPX. The relaxation induced by AMPPCP in the rat duodenum was however antagonized by an $A_{1}$-selective concentration of DPCPX, which confirms our previous conclusions (Hourani et al., 1991) that this agonist, although it is an ATP analogue which is resistant to degradation, acts entirely and directly via $P_{1}$-purinoceptors in this tissue, and has no $\mathbf{P}_{2 \mathrm{Y}}$ effect. That AMPPCP has apparently no effect on the $A_{2}$ receptors in the bladder whereas it is clearly an $A_{1}$ agonist in the duodenum, suggests that it is selective for $A_{1}$ receptors and has little $A_{2}$ agonist activity. This suggestion would be compatible with its rather weak $\mathbf{P}_{1}$ effect in the guinea-pig taenia caeci (Hourani et al., 1991), which also contains $A_{2}$ receptors (Burnstock \& Kennedy, 1985).

One surprising finding was the lack of potency of the $A_{2}$-selective agonist CGS 21680 in these tissues. In both the duodenum and the bladder it was much less potent than NECA, whereas it binds to rat brain $A_{2}$ receptors with an affinity roughly equal to NECA (Jarvis et al., 1989), and is roughly equipotent with NECA in relaxing a number of blood vessels (Balwierczak et al., 1991). $A_{2}$ receptors have been subdivided into $A_{2 a}$, which have a high affinity and are found in the striatum, and $A_{2 b}$ which have low affinity and are found elsewhere in the brain and in fibroblasts (Bruns et al., 1986; Lupica et al., 1990). CGS 21680 appears to bind only to the $A_{2 a}$ sites in rat brain (Jarvis et al., 1989), and one possible explanation for the lack of potency of CGS 21680 in the rat duodenum and bladder may therefore be that the $A_{2}$ receptors in these tissues are of the $A_{2 b}$ subtype. CGS 21680 has also been found to have very weak relaxant effects compared to NECA in the dog saphenous vein and guinea-pig aorta, and this has been interpreted as indicating the presence of $A_{2}$ receptors in these tissues (Hargreaves et al., 1991), although in the absence of any selective antagonists this cannot be confirmed.

In conclusion, we have shown that the $P_{1}$-purinoceptors on the rat duodenum are a mixture of $A_{1}$ and $A_{2}$, each mediating relaxation, and that the inhibitory $P_{1}$-purinoceptors on the rat bladder are of the $A_{2}$ subtype. The stable ATP analogue, AMPPCP, appears to act directly on the $A_{1}$ receptors but not on the $A_{2}$, in addition to its potent action on the contractile $P_{2 x}$ receptors in the bladder. In each tissue the $A_{28}$-selective agonist CGS 21680 has a very low potency, suggesting that the $A_{2}$ receptors may be of the low affinity $A_{2 b}$ subtype.

We thank the Royal Society for a Research Grant. J.N. is supported by an S.E.R.C. studentship.

\section{References}

BAILEY, S.J. \& HOURANI, S.M.O. (1990). A study of the purinoceptors mediating contraction in the rat colon. Br. J. Pharmacol., 100, 753-756.

BALWIERCZAK, J.L., SHARIF, R, KRULAN, C.M, FIELD, F.P, WEISS, G.B. \& MILLER, M.J.S. (1991). Comparative effects of a selective adenosine $\mathrm{A}_{2}$ receptor agonist, CGS 21680, and nitroprusside in vascular smooth muscle. Eur. J. Pharmacol., 196, 117-123.

BRUNS, R.F. (1990). Adenosine receptors: roles and pharmacology. Ann. N.Y. Acad. Sci., 603, 211-226.

BRUNS, R.F., LU, G.H. \& PUGSLEY, T.A. (1986). Characterization of the $\mathrm{A}_{2}$ adenosine receptor labeled by $\left[{ }^{3} \mathrm{H}\right] \mathrm{NECA}$ in rat striatal membranes. Mol. Pharmacol., 29, 331-346.

BURNSTOCK, G. (1990). Purinergic mechanisms. Ann. N.Y. Acad. Sci. 603, 1-17.

BURNSTOCK, G. \& KENNEDY, C. (1985). Is there a basis for distinguishing two types of $\mathrm{P}_{2}$-purinoceptor? Gen. Pharmacol., 16, 433-440.

COLLIS, M.G. (1990). Adenosine receptor sub-types in isolated tissues antagonist studies. In Purines in Cellular Signalling. ed. Jacobson, K.A., Daly, J.W. \& Manganiello, V. pp. 48-53. New York: Springer-Verlag.

COLLIS, M.G., JACOBSON, K.A. \& TOMKINS, D.M. (1987). Apparent affinity of some 8-phenyl-substituted xanthines at adenosine recep tors in guinea-pig aorta and atria. Br. J. Pharmacol., 92, 69-75.

COLLIS, M.G., STOGGALL, S.M. \& MARTIN, F.M. (1989). Apparent affinity of 1,3-dipropyl-8-cyclopentylxanthine for adenosine $A$ and $\mathrm{A}_{2}$ receptors in isolated tissues from guinea-pigs. $\mathrm{Br}$. J. Pharmacol., 97, 1274-1278.

CUSACK, N.J. \& HOURANI, S.M.O. (1990). Subtypes of $\mathbf{P}_{2}$-purinoceptors. Studies using analogues of ATP. Ann. N.Y. Acad. Sci., 603, 172-181.

FARMER, S.G., CANNING, B.J. \& WILKINS, D.E. (1988). Adenosine receptor-mediated contraction and relaxation of guinea-pig isolated tracheal smooth muscle; effects of adenosine antagonists. $\mathrm{Br}$. J. Pharmacol., 95, 371-378.

GORDON, J.L. (1986). Extracellular ATP: effects, sources and fate Biochem. J., 233, 309-319.

HARGREAVES, M.B., STOGGALL, S.M. \& COLLIS, M.G. (1991). Evidence that the adenosine receptor mediating relaxation in dog lateral saphenous vein and guinea-pig aorta is of the $A_{2 b}$ subtype. Br. J. Pharmacol., 102, 198P.

HOURANI, S.M.O., BAILEY, S.J., NICHOLLS, J. \& KITCHEN, I. (1991) Direct effects of adenylyl $5^{\prime}-(\beta, \gamma$-methylene $)$ diphosphonate, a stable ATP analogue, on relaxant $P_{1}$-purinoceptors in smooth muscle. Br. J. Pharmacol., 104, 685-690.

HUTCHISON, AJ, WEBB, R.L, OEI, H.H, GHAI, G.R, ZIMMERMAN, M.B. \& WILLIAMS, M. (1989). CGS $21680 \mathrm{C}$, an $\mathrm{A}_{2}$ selective adenosine receptor agonist with preferential hypotensive activity. $J$. Pharmacol. Exp. Ther., 251, 47-55.

JACOBSON, K.A. (1990). Adenosine $\left(\mathrm{P}_{1}\right)$ and ATP $\left(\mathrm{P}_{2}\right)$ receptors. In Comprehensive Medicinal Chemistry, Vol. 3, Membranes and Receptors. ed. Emmett, J.C. pp. 601-642. Oxford: Pergamon Press.

JARVIS, M.F., SCHULZ, R., HUTCHISON, A.J., DO, U.H., SILLS, M.A. \& WILLIAMS, M. (1989). [ $\left.{ }^{3} \mathrm{H}\right]$-CGS 21680 , a selective $A_{2}$ adenosine receptor agonist directly labels $A_{2}$ receptors in rat brain. J. Pharmacol. Exp. Ther., 251, 888-893.

KENNEDY, C. (1990). $P_{1}$ - and $P_{2}$-purinoceptor subtypes - an update. Arch. Int. Pharmacodyn., 303, 30-50.

LUPICA, C.R., CASS, W.A., ZAHNISER, N.R. \& DUNWIDDIE, T.V. (1990). Effects of the selective adenosine $A_{2}$ receptor agonist CGS 21680 on in vitro electrophysiology, cAMP formation and dopamine release in rat hippocampus and striatum. J. Pharmacol. Exp. Ther., 252, 1134-1141.

MANZINI, S., MAGGI, C.A. \& MELI, A. (1985). Further evidence for the involvement of adenosine 5 '-triphosphate in non-adrenergic noncholinergic relaxation of the isolated rat duodenum. Eur. J. Pharmacol., 113, 399-408.

NICHOLLS, J., HOURANI, S.M.O. \& KITCHEN, I. (1990). The ontogeny of purinoceptors in rat urinary bladder and duodenum. Br. J. Pharmacol., 100, 874-878.

RIBEIRO, J.A. \& SEBASTIAO, A.M. (1986). Adenosine receptors and calcium: basis for proposing a third $\left(\mathbf{A}_{3}\right)$ adenosine receptor. Proc. Neurobiol., 26, 179-209.

SLAKEY, L.L., GORDON, E.L. \& PEARSON, J.D. (1990). A comparison of ectonucleotidase activities on vascular endothelial and smooth muscle cells. Ann. N.Y. Acad. Sci., 603, 366-379.

STOGGALL, S.M. \& SHAW, J.S. (1990). The coexistence of adenosine $A_{1}$ and $\mathrm{A}_{2}$ receptors in guinea-pig aorta. Eur. J. Pharmacol., 190, 329-335.

WELFORD, L.A., CUSACK, N.J. \& HOURANI, S.M.O. (1986). ATP analogues and the guinea-pig taenia coli: a comparison of the structure-activity relationships of ectonucleotidases with those of the $\mathrm{P}_{2}$-purinoceptor. Eur. J. Pharmacol., 129, 217-224.

WELFORD, L.A., CUSACK, N.J. \& HOURANI, S.M.O. (1987). The structure-activity relationships of ectonucleotidases and of excitatory $\mathbf{P}_{2}$-purinoceptors: evidence that dephosphorylation of ATP analogues reduces pharmacological potency. Eur. J. Pharmacol., $141,123-130$.

WHITE T.D. (1988). Role of adenine compounds in autonomic neurotransmission. Pharmacol. Ther., 38, 129-168.

(Received August 23, 1991 